\title{
Aerosolised ribavirin in patients with advanced cryptogenic fibrosing alveolitis: a pilot study
}

\author{
Carlos Agustí, Antoni Xaubet, Eugeni Ballester, Antonio Alarcón, César Picado
}

\begin{abstract}
Background A report has recently been published concerning a patient with a cryptogenic fibrosing alveolitis who showed a striking improvement after being treated with the antiviral drug ribavirin (tribavirin, Virazid). The objective of this study was to further evaluate, in an open trial, the efficacy of rivabirin in cryptogenic fibrosing alveolitis.

Methods Ten patients (eight women) with advanced cryptogenic fibrosing alveolitis received aerosolised ribavirin (6 g/day for 15 days). Chest radiographs, lung function, and severity of dyspnoea were evaluated before and after two weeks of rivabirin treatment and also at three and 12 months.

Results No differences in radiographs, lung function impairment, or severity of dyspnoea were found after treatment. No side effects were detected.

Conclusions Administration of high doses of aerosolised ribavirin has no beneficial effects in patients with advanced cryptogenic fibrosing alveolitis.
\end{abstract}

(Thorax 1993;48:68-69)

Cryptogenic fibrosing alveolitis usually has a poor prognosis. ${ }^{1}$ The limited efficacy of steroids has led to the evaluation of other therapeutic agents, such as immunosuppressive drugs, chloroquine, or cyclosporin $\mathrm{A}$, which have occasionally caused some regression of the disease. $^{2-5}$

Recently, Prieto et al reported a patient with a desquamative interstitial pneumonia unresponsive to steroids and azathioprine, who showed a striking improvement in clinical symptoms and lung function after being treated with inhaled ribavirin. ${ }^{6}$ This isolated but encouraging single case report prompted us to conduct a pilot study to investigate if high doses of aerosolised ribavirin may be an effective treatment for patients with cryptogenic fibrosing alveolitis.

\section{Methods} POPULATION

The study population comprised 10 patients (eight women) with a mean age of 66 (SD 10) (range 46-81) years. Eight patients were nonsmokers and two gave up smoking at least five years before entry into the study. The diagnosis of cryptogenic fibrosis alveolitis was established by open lung biopsy in two patients and by the clinical criteria of Turner-Warwick $e t$ al in the remaining eight. ${ }^{7}$ The duration of patients' respiratory symptoms before their inclusion in the study was 41 (SD 12) months. At enrolment, patients were in a stable clinical condition and their lung function did not differ from that six months earlier. All patients except one were on regular corticosteroid treatment. One patient was also taking cyclophosphamide and another had previously received cyclosporin A. Five patients also inhaled bronchodilators. Treatment was not modified during the pilot study (including the dose of steroids and bronchodilators). Patients gave written consent after being informed about the experimental nature of the trial.

\section{INVESTIGATIONS}

Changes in clinical symptoms as well as chest radiographs and lung function were assessed after two weeks of ribavirin treatment and also three and 12 months later. Severity of dyspnoea and the distribution of inspiratory crackles were estimated on a standard five point scale. ${ }^{8}$ The extent of any alterations in chest radiographs was evaluated according to a three point scale (ILO/UC 1980). ${ }^{8}$ The lung function variables evaluated were forced vital capacity (FVC), total lung capacity (TLC), the single breath carbon monoxide transfer factor (TLCO), and arterial $\mathrm{PaO}_{2}$ during breathing of air. ${ }^{910}$

\section{TREATMENT WITH RIBAVIRIN (VIRAZID)}

Ribavirin was dissolved in sterile water ( $6 \mathrm{~g}$ of ribavirin in $300 \mathrm{ml}$ of sterile water) and delivered through a tight fitting face mask with a small particle aerosol generator (SPAG-2; ICN Pharmaceuticals INC, Costa Mesa, CA). This produced particles with a mass median aerodynamic diameter of $1.3 \mu \mathrm{m}$. The concentration in the reservoir chamber was $20 \mathrm{mg} / \mathrm{ml}$ Patients were admitted to the hospital and treated continuously for seven hours during each of the 14 days. To determine any possible side effects of ribavirin, serum urea, creatinine, and electrolyte concentrations, full blood count, and liver function were determined once each week and one and three months after treatment had finished.

\section{ANALYSIS}

Differences in lung function data between basal values and those obtained after treatment were assessed by means of one way analysis of variance and Sheffè's contrasts. Differences in clinical symptoms and radiographic changes were evaluated by the non-parametric Wilcoxon rank test. A p value below 0.05 was considered significant 
Clinical, radiological, and lung function variables after ribavirin treatment

\begin{tabular}{lccccl}
\hline & \multicolumn{2}{l}{ Time (months) } & \\
\cline { 2 - 5 } & 0 & $0 \cdot 5$ & 3 & 12 & $p$ \\
\hline Dyspnoea & $2 \cdot 4(1)$ & $2 \cdot 3(1 \cdot 1)$ & $2 \cdot 3(1)$ & $2 \cdot 7(0 \cdot 1)$ & NS \\
Chest $x$ ray film & $2 \cdot 5(0 \cdot 7)$ & $2 \cdot 4(0 \cdot 7)$ & $2 \cdot 4(0 \cdot 7)$ & $2 \cdot 8(0 \cdot 4)$ & NS \\
FVC $(\%)$ & $47(11)$ & $49(14)$ & $44(14)$ & $33(5)$ & $0 \cdot 02 \dagger$ \\
TLC $(\%)$ & $63(14)$ & $60(13)$ & $62(11)$ & $44(11)$ & NS \\
TLCO $(\%)$ & $41(12)$ & $48(13)$ & $46(17)$ & NA $\left(\frac{-}{1}\right)$ & NS \\
PaO $_{2}(\mathrm{kPa})$ & $9 \cdot 3(1 \cdot 7)$ & $9 \cdot 3(1 \cdot 5)$ & $9 \cdot 2(1 \cdot 1)$ & $7 \cdot 6(2 \cdot 1)$ & NS \\
\hline
\end{tabular}

*TLCo not measured for nine patients due to their limited ventilatory capacity.

†Significant differences between 0.5 and 12 months.

\section{Results}

At enrolment, patients were in an advanced stage of their disease, shown by the mean values of clinical, radiological, and lung function variables (table). As a group, the 10 patients with cryptogenic fibrosis alveolitis showed no differences in the chest radiographs, degree of impairment of lung function or severity of dyspnoea before or after the two week treatment with aerosolised ribavirin. Dyspnoea, chest radiographs, TLC, TLCO and $\mathrm{PaO}_{2}$ were unchanged at three and 12 months. There was a significant decline in FVC, however, at 12 months (table). Only one patient noticed a mild and durable relief of dyspnoea (from grade 2 to grade 1 ). This patient also had a $17 \%$ improvement in FVC (with no change in any other lung function variable) after two weeks of treatment. Subjective and functional improvement, however, was not maintained three months after completion of treatment in this patient (dyspnoea increased again to grade 2 and FVC deteriorated $14 \%$ from baseline).

\section{SIDE EFFECTS}

No clinical, biochemical, or haematological side effects were detected after treatment. Crystallisation of the drug was noted around the nostrils of all subjects after several hours of treatment.

\section{Discussion}

Since Prieto et $a l^{6}$ first reported one case of desquamative interstitial pneumonia that responded to aerosolised ribavirin, several authors have pointed out the necessity of performing clinical trials to evaluate this antiviral drug in cryptogenic fibrosis alveolitis. ${ }^{112}$ To our knowledge, this is the first prospective study in which the potentially beneficial effect of aerosolised ribavirin has been studied. Our results suggest that high doses of aerosolised ribavirin have no beneficial effects in patients with advanced cryptogenic fibrosis alveolitis. Nine patients did not notice any subjective changes and had no improvements on radiographs or in lung function at the end of treatment; similarly, the treatment did not prevent a progressive impairment of FVC in the 10 patients during a one year follow up period.

The total dose of aerosolised ribavirin received by the patients in the present study was much higher than the dose received by the patient reported by Prieto et $a l^{6}(84 \mathrm{~g} v 12 \mathrm{~g})$, who did experience a clinical and functional improvement. Despite our high dose, we have not been able to reproduce the results of Prieto et al. ${ }^{6}$ It may be argued that the lack of response could be due to differences in characteristics of the patients because the lung biopsy material of the patient described by Prieto et al was compatible with desquamative interstitial pneumonia, a type of pulmonary fibrosis with a greater response rate to anti-inflammatory treatment than the more fibrotic usual interstitial pneumonia. Some features of the case of Prieto et al suggest, however, that the response to ribavirin also occurred when there was long standing pulmonary fibrosis. Firstly, the lung biopsy material showed only small areas of alveolar desquamation and considerable established interstitial fibrosis; secondly, response to ribavirin took place after five years of the disease process, during which no response to glucocorticoids or azathioprine occurred, suggesting that the alveolitis component did not predominate; and, thirdly, the lung function capacity of the patient of Prieto et $a l^{6}$ was similar to that of the patients included in the present study.

In summary, our results show that high doses of aerosolised ribavirin are safe, but have no beneficial effects in patients with advanced cryptogenic fibrosis alveolitis. It would be necessary to confirm our results with controlled studies performed on patients at an earlier stage of their disease to definitively dismiss any possible benefits of aerosolised ribavirin in patients with cryptogenic fibrosis alveolitis.

We are indebted to Hubber SA Laboratory for technical and financial support.

1 Cherniack RM, Crystal RG, Kalica AR. Current concepts in idiopathic pulmonary fibrosis: A road map for the feature. Am Rev Respir Dis 1991;143:680-3.

2 Raghu G, Depaso WJ, Cain K, Hammar SP, Wetzel CE Dreis DF, et al. Azathioprine combined with prednisone in the treatment of idiopathic pulmonary fibrosis: A prospective double-blind, randomized, placebocontrolled clinical trial. Am Rev Respir Dis 1991;144: 291-6.

3 Johnson MA, Kwan S, Snell NJC, Nunn AJ, Darbyshire JH, Turner-Warwick M. Randomized controlled trial comparing prednisolone alone with cyclophosphamide and low dose prednisolone in combination in cryptogenic fibrosing alveolitis. Thorax 1989;44:280-8.

4 Haslam PL. Cryptogenic fibrosing alveolitis: pathogenic mechanisms and therapeutic approaches. Eur Respir $J$ 1990;3:355-7.

5 Alton EW, Johnson M, Turner-Warwick M. Advanced cryptogenic fibrosing alveolitis: preliminary report on treatment with cyclosporin A. Respiratory Medicine 1989; 83:277-9.

6 Prieto J, Sangro B, Beloqui O. Ribavirin in desquamative interstitial pneumonia. Chest 1988;93:446-7.

7 Turner-Warwick M, Burrows B, Johnson A. Cryptogenic fibrosing alveolitis: clinical features and their influence on survival. Thorax 1980;35:171-80.

8 Xaubet A, Rodriguez-Roisin R, Bombi JA, Marin A, Roca J, Agusti Vidal A. Correlation of bronchoalveolar lavage and clinical and functional findings in asbestosis. Am Rev Respir Dis 1986;133:848-54.

9 Roca J, Sanchis J, Agusti-Vidal A, Segarra F, Navadas D, Rodriguez-Roisin $\mathrm{R}$, et al. Spirometric reference values for a mediterranean population. Bull Europ Physiopathol Respir 1986;22:217-24.

10 Roca J, Rodriguez-Roisin R, Cobo E, Burgos F, Pérez J, Clausen JL. Single-breath carbon monoxide diffusing capacity $\left(\mathrm{DL}_{\mathrm{co}}\right)$ prediction equations for a mediterranean population. Am Rev Respir Dis 1990;140:1026-32.

11 Haslam PL. Cryptogenic fibrosing alveolitis: pathogenic mechanisms and therapeutic approaches. Eur Respir $J$ 1990;3:355-7.

12 Han LY, Wilson R, Slater S, Rutman A, Read RC, Snell NDC, et al. In vitro and in vivo effects of ribavirin on human respiratory epithelium. Thorax 1990;45:100-4. 